\title{
Atuação de Enfermeiras Oncologistas no Banco Nacional de Tumores: Iniciativa Pioneira do Instituto Nacional de Câncer José Alencar Gomes da Silva, Brasil
} Practice of Oncologist Nurses at the National Tumor Bank: Pioneering Initiative of the Brazilian National Cancer Institute - José Alencar Gomes da Silva, Brazil Actuación de Enfermeras Oncólogas en el Banco Nacional de Tumores: Iniciativa Pionera del Instituto Nacional del Cáncer José Alencar Gomes da Silva, Brasil

\author{
Maria Teresa dos Santos Guedes'; Maria Inêz Rocha Moitaㄹ; Maria Cristina Ramos Goulart Caldas ${ }^{3}$; Valdete Oliveira Santos ${ }^{4}$; Maria Cristina Marques \\ dos Santos 5
}

\section{INTRODUÇÃO}

A divulgação do sequenciamento do genoma humano incrementou estudos sobre as bases moleculares e genéticas do câncer e possibilitou avanços em oncologia, sendo necessária a criação de bancos ou biobancos de tecidos humanos que facilitassem a pesquisa translacional e análises moleculares ${ }^{1}$.

De acordo com a resoluçáo $441 / 11^{2}$ e a portaria $2.201 / 11^{3}$, esses biobancos são locais que guardam coleçôes organizadas de material biológico humano com preservação de RNA e DNA, associadas a informaçóes clínicas e epidemiológicas para fins de pesquisa, seguindo normas técnicas, éticas e operacionais, sob responsabilidade de instituiçóes públicas ou privadas. Essa forma de armazenamento é essencial à pesquisa molecular ${ }^{4}$ voltada para a caracterização de doenças, indo da epidemiologia e classificação diagnóstica e prognóstica até avaliação da resposta terapêutica ${ }^{1}$.

Por isso, o Instituto Nacional de Câncer José Alencar Gomes da Silva (INCA), estabelecido como Centro de Referência de Alta Complexidade do Ministério da Saúde (MS) pela portaria 2.439/GM/20055 , implantou o Banco
Nacional de Tumores e DNA (BNT) em 2005. Uma de suas finalidades é a formação de uma rede nacional e latino-americana para coleta de espécimes biológicas e troca de informaçóes, reunindo dados sobre o perfil genético da população brasileira e da América Latina para estudos voltados ao aprimoramento da assistência aos portadores de câncer ${ }^{6}$.

Agregando valor às amostras de tumores, desde seu início, o BNT adotou como rotina a coleta de dados epidemiológicos como informaçôes sociodemográficas, estilo de vida, exposição ambiental e ocupacional, história familiar de câncer e dados clínicos, durante entrevista com o paciente. E, para preservar os preceitos éticos, a amostra biológica é obtida somente após consentimento (TCLE) do paciente, cumprindo a Resolução 196/96 do Conselho Nacional de Saúde e a Declaração Universal sobre o Genoma Humano e Direitos Humanos da Unesco 7 .

Para desenvolver tais atividades, enfermeiras oncologistas foram incluídas na equipe do BNT, tornando o INCA pioneiro na adoção dessa categoria profissional em um biobanco. Essa iniciativa do INCA já conta com seis anos de uma bem-sucedida experiência que, além de tudo, cumpriu um dos objetivos do projeto do

\footnotetext{
${ }^{1}$ Coordenadora de Enfermagem do Banco Nacional de Tumores e DNA (BNT) do Instituto Nacional de Câncer José Alencar Gomes da Silva (INCA). Mestre em Enfermagem pela Universidade Federal do Estado do Rio de Janeiro (UNIRIO). E-mail: teresaguedes@inca.gov.br.

${ }^{2}$ Chefe do Serviço de Enfermagem Ambulatorial do Hospital do Câncer III (HCIII/INCA). Pós-graduada em Enfermagem em Oncologia pelo INCA e pela Universidade Federal do Rio de Janeiro (UFRJ).E-mail: amb.hc3@inca.gov.br.

${ }^{3}$ Chefe da Divisão de Enfermagem do HC III/INCA. Pós-Graduada em Administração Hospitalar pela Universidade Estadual do Rio de Janeiro (UERJ). E-mail:mcaldas@inca.gov.br.

${ }^{4}$ Chefe do Serviço de Enfermagem em Procedimentos Externos do Hospital do Câncer I (HCI/INCA). Mestre em Enfermagem pela UFRJ. E-mail: vsantos@inca.gov.br. ${ }^{5}$ Enfermeira do Ambulatório de Cirurgia de Cabeça e Pescoço do HCI/INCA. Pós-graduada em Administração Hospitalar pela UERJ. E-mail: maria.cristina@inca.gov.br.
} 
BNT, aquele que previa o impacto em recursos humanos através da geração de conhecimento, capacitação técnica e introduçáo de novos procedimentos a serem realizados pelo corpo de profissionais da instituição ${ }^{8}$, no caso aqui específico, cumprido a partir da inserção das enfermeiras oncologistas nesse projeto.

\section{A ATUAÇÃO DAS ENFERMEIRAS NO BNT-INCA}

A atuação de enfermeiras no BNT sustenta-se na Lei do Exercício Profissional de Enfermagem no 7.498/86², a qual determina como privativas dessa categoria profissional as açôes de planejamento, organização, coordenação, execução e avaliação de serviços de saúde e atividades de maior complexidade que exijam conhecimentos científicos adequados e capacidade para tomar decisôes críticas, como as que caracterizam os serviços de pesquisa.

Uma peculiaridade das enfermeiras é o conhecimento de toda estrutura e do dinamismo hospitalar, além da rotina de atendimento e do fluxo de pacientes. Provavelmente, por esse aspecto, costumam ser profissionais mais tolerantes às experimentaçóes e à diversidade de tarefas, tornando-se pessoas criativas, comunicativas e políticas, que pensam "fora da caixa", termo explicado por Marcos Cavalcant $\mathrm{i}^{10}$ ao se referir ao conhecimento tácito utilizado na prática pelos profissionais, ou seja, aquele saber que é construído a partir da experiência vivida, gerado por reflexão, concentraçáo e investimento pessoal. Esse conhecimento ajuda a criar alternativas para solucionar problemas e implementar um novo serviço como o BNT.

A primeira proposta de trabalho para as enfermeiras no BNT-INCA previa apenas obtençáo de TCLE e entrevista para coleta de dados epidemiológicos dos pacientes; porém algumas peculiaridades dessa categoria favoreceram a uma maior participaçáo na fase de implantação do BNT: sua visão sistêmica da dinâmica de funcionamento da instituição e o foco no capital humano, nosso bem intangível.

$\mathrm{O}$ conhecimento especializado em oncologia e a participação ativa das enfermeiras no trabalho institucional produziram uma relação de confiança e credibilidade junto à equipe profissional e aos pacientes. Isso se tornou vital para o planejamento e operacionalização integral dos processos de trabalho e para construção dos fluxos de atendimento, auxiliando na implantação e desenvolvimento do biobanco na instituição.

Efetivamente, a participação da enfermeira no BNTINCA foi iniciada em 3 de abril de 2006, quando foi incluído o primeiro paciente que aceitou ceder amostra biológica.

Hoje, a atuação da enfermeira no biobanco abrange aspectos de planejamento, coordenaçáo e implantação das atividades de captação de cedentes, como são denominados aqueles pacientes que aceitam nos ceder espécimes biológicos. Além disso, as enfermeiras participam da educação em serviço dos seus pares e de outros profissionais que necessitem de capacitação, indispensável ao processo de desenvolvimento de parceria do INCA com centros interessados em formar rede com o BNT, tanto no Brasil como no restante da América Latina.

Focando na pessoa com câncer e seus familiares, a atividade das enfermeiras foi desenvolvida respeitando a sua autonomia de decidir, favoravelmente ou não, pela cessão de amostra de tecido, e preservando a confidencialidade das informaçôes coletadas ${ }^{11,12}$. Alguns preceitos foram adotados na escolha do local adequado para se desenvolver a interaçáo apropriada com pacientes e familiares, a saber:

1. Convite ao paciente feito num momento em que não se sentisse coagido, como na véspera de cirurgias, procedimentos diagnósticos ou durante os mesmos.

2. Entrevistas em ambiente privado, acolhedor e seguro, para garantir autonomia dos pacientes, sigilo sobre a decisão de ceder ou não amostras e informaçôes coletadas. 3. Ampliação da oportunidade para coleta de amostras, considerando o perfil dos pacientes (mais de 75\% recebem primeiramente quimioterapia e radioterapia ao invés de cirurgia). Decidiu-se que o melhor momento para abordagem seria logo após a matrícula, favorecendo coleta de amostras durante exames de estadiamento ou pré-operatórios. Assim, no pré-tratamento oncológico, amostras de tecidos sem degradação de RNA e DNA podem ser coletadas em punçóes guiadas por exames de imagens, endoscopias digestivas, colonoscopias, retossigmoidoscopias, broncoscopias ou exames laboratoriais. Também são coletadas amostras em peças cirúrgicas após cirurgias eletivas.

4. Ter referência de um local, com profissional disponível para esclarecer dúvidas aos pacientes, acrescentar novas informaçóes sobre seus hábitos ou sua família ou para desistir da cessão de espécimes, atendendo aos preceitos éticos.

Assim, o ambulatório das unidades do INCA foi o local ideal escolhido para a captação e inclusão de cedentes de espécimes biológicos. Em 18 de abril de 2008, foi inaugurada a primeira Central de Captação do BNT no INCA.

Nas Centrais de Captação do BNT no INCA, o trabalho da enfermeira é pró-ativo no recrutamento e captação de pacientes. A abordagem aos pacientes acompanhados de seus familiares é feita após seleção seguindo critérios de elegibilidade das especialidades oncológicas para criar coleçốes de tumores e tecidos ou focando nos projetos de pesquisa em execução. Uma síntese dos possíveis passos do processo de captação, seleção e inclusão dos pacientes cedentes é apresentada no Quadro 1.

Alguns estudos ${ }^{11,13-14}$ demonstraram que enfermeiras são positivamente favoráveis a atividades de pesquisas, percebem os aspectos éticos envolvidos e entendem que os princípios da beneficência, justiça e autonomia devem ser aplicados na sua rotina diária, procurando contribuir favoravelmente com instituição e pacientes. 
Quadro 1. Etapas do processo de seleção e inclusão de pacientes cedentes de amostras biológicas ao BNT

\begin{tabular}{|c|c|}
\hline $\begin{array}{l}\text { Passos do processo de captação de } \\
\text { cedentes }\end{array}$ & Justificativas \\
\hline $\begin{array}{l}\text { Seleção do possível cedente de amostras } \\
\text { biológicas }\end{array}$ & $\begin{array}{l}\text { Abordar, no ato da matrícula, pacientes que atendem aos critérios } \\
\text { de seleção específicos da clínica ou dos projetos de pesquisa } \\
\text { aprovados } \\
\text { Previamente, conhecer diagnóstico e condições clínicas, sociais } \\
\text { e emocionais dos pacientes ou condições que os impeçam de } \\
\text { decidir a cessão de amostras ou serem abordados naquele } \\
\text { momento }\end{array}$ \\
\hline $\begin{array}{l}\text { Levantamento dos tipos de exames já } \\
\text { feitos e dos que ainda estão por fazer }\end{array}$ & $\begin{array}{l}\text { Buscar possibilidades de coleta de amostras durante } \\
\text { procedimentos invasivos que serão realizados futuramente }\end{array}$ \\
\hline $\begin{array}{l}\text { Levantamento das datas de agendamento } \\
\text { de consultas ou exames }\end{array}$ & $\begin{array}{l}\text { Identificar datas em que o paciente estará no hospital para, se } \\
\text { necessário, conciliar entrevista nesses dias, o que economiza } \\
\text { tempo, recurso financeiro e desgaste físico do paciente e familiar }\end{array}$ \\
\hline Abordagem c & $\begin{array}{l}\text { Explicar o que é BNT e sua finalidade. Convidá-lo para cessão do } \\
\text { material biológico. Avaliar condições cognitivas, de estado clínico } \\
\text { e nível de consciência, certificando-se que o paciente esteja em } \\
\text { condições de decidir algo, evitando coação }\end{array}$ \\
\hline $\begin{array}{l}\text { Garantia da privacidade e direitos } \\
\text { dos possíveis cedentes, atendendo às } \\
\text { exigências da Res. CNS n. 196/96 e } \\
441 / 11\end{array}$ & $\begin{array}{l}\text { Usar ambiente seguro e privativo para o paciente, sem } \\
\text { constrangimento na tomada de decisão pela cessão de amostras } \\
\text { e ao aplicar o termo de consentimento ( } 3 \text { vias, } 1 \text { é do paciente) } \\
\text { e coletar os dados epidemiológicos. Registrar a cessão no } \\
\text { prontuário }\end{array}$ \\
\hline $\begin{array}{l}\text { Identificação de necessidades afetadas nos } \\
\text { pacientes }\end{array}$ & $\begin{array}{l}\text { O acolhimento inclui esclarecimento de dúvidas sobre a rotina } \\
\text { institucional, exames diagnósticos, uso de medicamentos, } \\
\text { procedimentos cirúrgicos, encaminhamentos de problemas } \\
\text { colaborativos (Serviço Social, Nutrição, Fisioterapia, Psicologia, } \\
\text { Voluntariado ou médicos), e também informação quanto a sinais } \\
\text { de complicações decorrentes do adoecimento por câncer }\end{array}$ \\
\hline
\end{tabular}

Nessa concepção, o INCA é uma instituição de pesquisa, assistência e ensino em oncologia; e, assim, as enfermeiras do BNT têm contribuído positivamente com os pacientes e com a Instituição prestando suporte à pesquisa, ao tratamento dos pacientes, a educaçáo continuada e ao ensino na pós-graduação, nesse último aspecto, inclusive, com a produção de duas monografias relacionadas à atuação da enfermeira no referido contexto.

Desde 1996, Nascimento e Souza ${ }^{15}$ apontavam a importância da divulgação de vivências práticas das enfermeiras, a fim de contemplar o trinômio arte-ciênciatecnologia, que caracteriza esses profissionais. As autoras alertavam que sem divulgação do seu fazer os enfermeiros náo contribuem para a evolução de sua profissáo, pois náo se apropriam de suas ideias, resultantes da atividade intelectual geradora de tecnologias. Nesse sentido, e entendendo ainda que na pesquisa é imprescindível atualização e troca de conhecimento, foi realizado o $I$ Encontro de Enfermeiros de Bancos de Tumores, ocorrido nos dias 1 e 2 de julho de 2009, paralelamente ao II Fórum Nacional do Banco Nacional de Tumores.
Também foi desenvolvido pelas enfermeiras do BNTINCA um projeto intitulado "Análise da consistência da história familiar de câncer de doadoras do Banco Nacional de Tumores e DNA" (registro Comitê de Ética-INCA n ${ }^{\circ}$. $110 / 11$ ), cujo tema foi a entrevista para coleta da história familiar de câncer, a qual permite levantamento de risco para outros tipos de câncer no mesmo paciente e entre seus familiares, e oportuniza açóes educativas e preventivas, ajudando a população a se manter saudável. Esse projeto permitiu que o BNT recebesse apoio do Programa para Ações Estratégicas de Pesquisa e Desenvolvimento do INCA/MS, que concedeu bolsas a enfermeiras para as unidades de Ginecologia e Mastologia.

A Coordenação de Enfermagem do BNT-INCA criou ainda um indicador de desempenho para as enfermeiras bolsistas participantes das atividades do banco denominado "Percentual de captação e inclusão de cedentes para o BNT". O levantamento desse indicador na unidade de Mastologia, no ano de 2011, mostrou que, de 1.365 pacientes admitidas, 1.073 pacientes $(78,6 \%)$ consentiram ceder material ao BNT; 228 se extraviaram 
$(16,7 \%)$ do fluxo por intercorrências clínicas emergenciais; e outras $54(3,95 \%)$ recusaram a cessão, sendo considerado um ótimo resultado, tanto na capacidade de captação como na alta taxa de consentimentos obtidos.

\section{CONCLUSÃO}

A inserção de enfermeiras no projeto do BNT-INCA mostrou-se vantajosa e uma experiência exitosa devido à sua participação no fluxo de recepção ambulatorial, por estarem integradas à equipe multiprofissional e favorecendo o acolhimento de pessoas com câncer num momento tão difícil de suas vidas, ao darem o primeiro passo para tratamento de uma doença considerada devastadora.

Além disso, a presença ativa das enfermeiras facilita a captação de cedentes de amostras biológicas, a coleta de dados epidemiológicos e a avaliação preliminar para casos que merecem abordagem pela equipe de Aconselhamento Genético, colaborando, assim, para o controle de uma patologia que está em segundo lugar como causa de morte por doença em nosso país.

Finalmente, as enfermeiras foram profissionais relevantes para a estruturação inicial do BNTINCA e continuam sendo para a manutenção de sua operacionalização dentro do Instituto.

\section{CONTRIBUIÇÕES}

Maria Teresa dos Santos Guedes participou da concepçáo e planejamento do projeto do artigo; obtenção, análise e interpretação de dados; redação e revisão crítica do texto. Maria Inêz Rocha Moita e Maria Cristina Ramos Goulart Caldas participaram da obtenção, análise e interpretação de dados; redação e revisão crítica do texto. Valdete Oliveira Santos e Maria Cristina Marques dos Santos participaram da redação e revisão crítica do texto.

\section{Declaraçáo de Conflito de Interesses: Nada a Declarar.}

\section{REFERÊNCIAS}

1. Parmigiani RB, Camargo AA. O genoma humano e o câncer. In: Ferreira CG; Rocha JCC (Org). Oncologia molecular. São Paulo: Ed Atheneu; 2010, p.3-13.

2. Conselho Nacional de Saúde (Brasil). Resolução no 441, de 12 de maio de 2011. Estabelece as diretrizes e normas para armazenamento e utilização de material biológico humano com finalidade de pesquisas. [Internet]. 2011 [acesso em 2012 ago 01]. Disponível em <http:// conselho.saude.gov.br/resolucoes/2011/Reso441.pdf>.

3. Brasil. Ministério da Saúde. Portaria No 2201, de 14 de setembro de 2011. Estabelece as diretrizes nacionais para biorrepositório e biobanco de material biológico humano com finalidade de pesquisa. [Internet]. 2011 [acesso 2012 jul 20]. Disponível em <http:// www.brasilsus.com.br/legislacoes/gm/109651-2201. html?tmpl=component\&pri>.

4. Carvalho L, Bernardo MT, Tavares M, Cotovio P, Mação P, Oliveira C. Banco de Tumores: imperativo na medicina. Acta Med Port. 2007; 20(4): 325-334.

5. Brasil. Ministério da Saúde. Portaria 2.439/GM/2005, de 08 de dezembro de 2005. Estabelece o Instituto Nacional de Câncer (INCA) como Centro de Referência de Alta Complexidade do Ministério da Saúde. [Internet]. 2005 [acesso 2012 ago 01]. Disponível em <http://dtr2001.saude. gov.br/sas/PORTARIAS/Port2005/GM/GM-2439.htm>.

6. Conselho Nacional de Saúde (Brasil). Resolução no 196/96, de 10 de outubro de 1996. Estabelece as diretrizes e normas regulamentadoras de pesquisa envolvendo seres humanos. [Internet]. 1996 [acesso 2012 ago 01]. Disponível em <http://www.bioetica.ufrgs. $\mathrm{br} / \mathrm{res} 19696 . \mathrm{htm}>$.

7. Organização das Nações Unidas para a Educação, a Ciência e a Cultura. Declaração universal do genoma humano e dos direitos humanos. [Internet]. 2001 [acesso 2012 ago 01]. Disponível em < http://unesdoc.unesco. org/images/0012/001229/122990por.pdf>.

8. Instituto Nacional de Câncer José Alencar de Oliveira Gomes da Silva. Banco nacional de tumores e DNA: esquema teórico. [Internet]. 2012 [acesso 2012 ago 01]. Disponível em <http://wwwl.inca.gov.br/conteudo_ view.asp?id $=1329>$.

9. Brasil. Lei No. 7.498, de 25 de junho de 1986. Regulamenta o exercício da enfermagem. Diário Oficial da União. [Internet]. 1986 Jun 26; seção I, fls. 9.2739.275. [acesso 2012 jul 20]. Disponível em: <http:// www.jusbrasil.com.br/diarios/3519139/dou-secao-1-2606-1986-pg-1/pdfView >

10. Cavalcanti M, Nepomuceno C. Conhecimento em rede: como implantar projetos de inteligência coletiva. 2. ed. Rio de Janeiro: Editora Campus-Elsevier, 2007.

11. Scott PA, Välimäki M, Leino-Kilpi H, Dassen T, Gasull $\mathrm{M}$, Lemonidou C. et al. Autonomy, privacy and informed consent 1: concepts and definitions. Br J Nurs. 2003; 12(1):43-7.

12. Garrafa V. Respeito à autonomia e livre consentimento em pesquisas com material biológico armazenado [editorial]. Rev Assoc Med Bras (1992). 2010; 56(5):493516

13. Swift $P$. Ethical considerations in research from a cancer nurse's perspective. Prof Nurse. 2002; 18(3):171-5.

14. Beadle G, Mengersen K, Moynihan S, Yates P. Perceptions of the ethical conduct of cancer trials by oncology nurses. Eur J Cancer Care (Engl). 2011; 20(5):585-92.

15. Nascimento MAL, Souza EF. Da ciência e arte na enfermagem à tecnologia e industrialização [edição extra]. Rev enferm UERJ. 1996; 119-123. 